\title{
Should All Children Admitted with Community Acquired Pneumonia have Blood Cultures Taken? Correspondence
}

\author{
Sora Yasri • Viroj Wiwanitkit
}

Received: 3 September 2014 / Accepted: 21 November 2014 / Published online: 18 December 2014

(C) Dr. K C Chaudhuri Foundation 2014

To the Editor: We would like to discuss on the article entitled "Should all children admitted with community acquired pneumonia have blood cultures taken?" recently published online in Indian Journal of Pediatrics [1]. Lai et al; noted that "both the yield and the impact of blood culture results on the adjustment of empiric antibiotic treatment were very small [1]" and "there was a high contamination rate [1]." The consideration is on the quality of present blood collection for blood culture. The poor collection technique can be the reason for high contamination and low yield. In the setting of Lai et al., the problem of "pre-analytical error" should be systematically assessed and corrected. It should be noted the preanalytical error is the main reason for poor analytical result and it can be seen at a high rate despite the laboratory being internationally accredited [2]. The problem can be seen in many countries including USA [3]. The new guideline that focuses on the rational use and quality control of laboratory investigations is important and should be applied for any setting [4]. In a setting with good laboratory quality control system, the contamination rate will be low and the positive blood cultures can be useful for "prompt change to narrowspectrum antibiotic therapy [5]."
Conflict of Interest None.

Source of Funding None.

\section{References}

1. Lai EM, Nathan AM, de Bruyne JA, Chan LL. Should all children admitted with community acquired pneumonia have blood cultures taken? Indian J Pediatr. 2014. doi:10.1007/s12098-0141565-6.

2. Wiwanitkit V. Types and frequency of preanalytical mistakes in the first Thai ISO 9002:1994 certified clinical laboratory, a 6 - month monitoring. BMC Clin Pathol. 2001;1:5.

3. Parikh K, Davis AB, Pavuluri P. Do we need this blood culture? Hosp Pediatr. 2014;4:78-84.

4. Elemraid MA, Rushton SP, Thomas MF, Spencer DA, Eastham KM, Gennery AR, et al; North East of England Paediatric Respiratory Infection Study Group. Changing clinical practice: management of paediatric community-acquired pneumonia. J Eval Clin Pract. 2014;20:94-9.

5. Myers AL, Hall M, Williams DJ, Auger K, Tieder JS, Statile A, et al. Prevalence of bacteremia in hospitalized pediatric patients with community-acquired pneumonia. Pediatr Infect Dis J. 2013;32: 736-40.

S. Yasri $(\triangle)$

KMT Primary Care Center, Bangkok, Thailand 10550

e-mail: sorayasri@outlook.co.th

V. Wiwanitkit

Department of Tropical Medicine and Public Health, Hainan Medical

University, Hainan, China 